USING SENTENCE ENHANCEMENTS TO

DISTINGUISH BETWEEN DETERRENCE AND INCAPACITATION

Daniel Kessler

Steven D. Levitt

Working Paper 6484 
NBER WORKING PAPER SERIES

\title{
USING SENTENCE ENHANCEMENTS TO DISTINGUISH BETWEEN DETERRENCE AND INCAPACITATION
}

\author{
Daniel Kessler
}

Steven D. Levitt

Working Paper 6484

http://www.nber.org/papers/w6484

\section{NATIONAL BUREAU OF ECONOMIC RESEARCH 1050 Massachusetts Avenue \\ Cambridge, MA 02138 \\ March 1998}

We would like to thank John Donohue, Isaac Ehrlich, Edward Glaeser, Austan Goolsbee, John Lott, Anne Piehl, conference participants, and especially Bruce Kobayashi for comments and suggestions. Financial support of the National Science Foundation through the NBER is gratefully acknowledged. Justin Wood and David Becker provided outstanding research assistance. Any opinions expressed are those of the authors and not those of the National Bureau of Economic Research.

(C) 1998 by Daniel Kessler and Steven D. Levitt. All rights reserved. Short sections of text, not to exceed two paragraphs, may be quoted without explicit permission provided that full credit, including (C) notice, is given to the source.

Using Sentence Enhancements to Distinguish 
between Deterrence and Incapacitation

Daniel Kessler and Steven D. Levitt

NBER Working Paper No. 6484

March 1998

\begin{abstract}
It is typically difficult to differentiate empirically between deterrence and incapacitation since both are a function of expected punishment. In this paper we demonstrate that the introduction of sentence enhancements (i.e. increased punishments that are added on to prison sentences that would have been served anyway) provides a direct means of measuring deterrence. Because the criminal would have been sentenced to prison anyway, there is no additional incapacitation effect from the sentence enhancement in the short-run. Therefore, any immediate decrease in crime must be due to deterrence. We test the model using California's Proposition 8 which imposed sentence enhancements for a selected group of crimes. In the year following its passage, crimes covered by Proposition 8 fell by more than 10 percent relative to similar crimes not affected by the law, suggesting a large deterrent effect. Three years after the law comes into effect, eligible crimes have fallen roughly 20-40 percent compared to non-eligible crimes. This large deterrent effect suggests that sentence enhancements, and "three-strikes" laws in particular, may be more cost-effective than is generally thought.
\end{abstract}

Daniel Kessler

Graduate School of Business

Stanford University

Stanford, CA 94305

and NBER

fkessler@GSB-pound.stanford.edu
Steven D. Levitt

Department of Economics

University of Chicago

Chicago, IL 60637

and NBER

slevitt@midway.uchicago.edu 
Since Gary Becker's seminal paper on the economic model of crime (Becker 1968), there have been more than one hundred published studies attempting to test for deterrence. ${ }^{1}$ While there is disaggreement on the topic, many studies published in recent years have found results that are at a minimum consistent with the presence of an important deterrence effect using a range of different measures (e.g. Ehrlich 1973, Grogger 1991, Levitt 1996, Marvell and Moody 1994, Marvell and Moody 1996, Mayhew et al. 1979, Tauchen et al. 1994, Witte 1980).

One important shortcoming associated with almost all of these empirical analyses, however, is the difficulty in distinguishing between deterrence and incapacitation. As long as the primary means of punishment is imprisonment, policy changes that increase the expected punishment per crime lead to both greater deterrence and greater incapacitation. Consequently, most empirical tests of deterrence are, in practice, joint tests of deterrence and incapacitation. For example, reductions in crime associated with increased arrest rates or rising prison populations are consistent with the presence of deterrence, incapacitation, or both. Given the strong evidence in support of incapacitation effects (Visher 1986, Dilulio and Piehl 1991, Spelman 1994), caution is warranted in attributing a causal role to deterrence in such contexts. ${ }^{2}$

In this paper, we present a novel approach to separating deterrence from incapacitation. We exploit the unique transition path associated with what are commonly termed "sentence

'Surveys of this literature include Cameron (1988), Ehrlich (1996), and Nagin (1997).

2 There are a few studies that make an attempt to carefully differentiate between deterrence and incapacitation. McCormick and Tollison (1984) analyze the impact of increasing the number of basketball referees on the frequency with which fouls are committed. Because the punishment in this context is not incarceration, the effects that they obtain are solely deterrencerelated. Levitt (1998) attempts to distinguish between deterrence and incapacitation using the impact of increased arrest rates for one crime on the frequency with which other crimes are committed. 
enhancements." With sentence enhancements, additional prison time is tacked on to the basic sentence for crimes of a particular type, e.g. crimes committed with a gun, or third convictions for qualifying crimes in the presence of "three strikes" laws. ${ }^{3}$ The key insight of the analysis is that initially such laws may have a deterrent effect, but will not have any impact on the amount of incapacitation. The criminal is already required to serve the basic sentence. Only after that term ${ }^{4}$ has elapsed and the sentence enhancement takes effect will there be an added incapacitation effect. The deterrence effect, on the other hand, will begin immediately as the criminal incorporates the increased punishment associated with the sentence enhancement into the decision calculus. To the extent that there are lags in behavioral changes on the part of criminals, or the new laws are not immediately credible, the initial decline in crime will be only a fraction of the long-run deterrence. Thus, changes in crime immediately following the introduction of a sentence enhancement provide a lower bound on the long-run deterrence effect.

We begin the paper by developing a theoretical model that formalizes the intuition of the preceding paragraph. We then provide an empirical test of the model using California's experiences with Proposition 8, a popular referendum passed in 1982 that increased the scope and severity of repeat-offender enhancements. In the years immediately following Proposition 8, crime rates for those offenses covered by the sentence enhancements fell sharply, both in absolute terms and relative to a set of similar offenses that were excluded from Proposition 8.

${ }^{3}$ As discussed in the following section of the paper, there has been a substantial movement towards a variety of sentence enhancements in the United States in recent years. For instance, since 1993, three-strikes laws have been adopted in 24 states and have been added to the Federal sentencing guidelines. These laws are in addition to a range of repeat offender and gun enhancements already in place in the great majority of states.

${ }^{4}$ Or more precisely, the proportion of that sentence that would have actually been served. 
These results represent a sharp break from the time path of crime before enactment of the law. The crimes covered by Proposition 8 were actually increasing at a faster rate than the excluded crimes categories prior to passage of the law. These results are consistent with the presence of a large deterrent effect of the sentence enhancements. Furthermore, the continued decline over the ensuing years in relative crime rates for the offenses covered by Proposition 8 are consistent with the models prediction that the transition to a new steady state will involve a continued fall in crime as any lagged deterrence or incapacitative impact of the enhancements takes effect.

Differentiating between deterrence and incapacitation is not merely an academic exercise. The distinction between those two forces is critical to determining the costs and benefits associated with sentence enhancements, particularly for three-strikes laws which entail extremely long sentences. If incapacitation is the primary force, than three-strikes laws will lead to enormous increases in the number of prisoners and eventually a geriatric prison population that has largely aged out of crime, poses little threat to society, and requires costly health care (Blumstein 1995, Flynn et al. 1997). In contrast, as demonstrated in the model, if deterrence is the operative force, than three strikes laws will lead to an equilibrium with both lower crime and lower levels of incarceration, making it a very attractive policy. To the extent that the large deterrence effects we identify in the Proposition 8 example are generalizable, our results suggest that, if enforced, three-strikes laws and other sentence enhancements may be a cost-effective approach to fighting crime.

The structure of the paper is as follows. Section I presents the theoretical model of sentence enhacements, demonstrating formally how deterrence and incapacitation can be distinguished. The second section examines the use of sentence enhancements in the United 
States. Section III provides an empirical test of the theoretical model using the response of crime rates to Proposition 8 in California. The final section considers the broader implications of our findings, particularly with respect to three-strikes laws.

\section{Section I: Theoretical Model}

In this section we develop a stylized economic model of crime incorporating sentence enhancements into the analysis. We characterize both the steady-state equilibria with and without sentence enhancements, as well as the transition path when sentence enhancements are introduced into an economy.

For simplicity, we consider a model with a continuum of infinitely-lived agents. ${ }^{5}$ In every period, each individual chooses either to engage in a single criminal act or in the non-crime alternative (except those who are currently incarcerated, who do neither). If the agent commits a crime in period t, there is an exogenously given, predetermined likelihood of detection $(p)$. The punishment, conditional on being caught committing a crime, is a prison sentence of $S$ periods that begins in period $t+1$ and runs through period $t+S+1 .^{6}$ While incarcerated, the agent is unable to commit further crimes. The utility loss associated with this prison sentence is denoted

5 The results that we derive would continue to hold in an overlapping generations framework or in a model with finite-lived agents. Limiting the focus to one cohort, however, greatly simplifies both the notation and calculations.

${ }^{6}$ Both the likelihood of punishment and the length of the prison sentence could be endogenized to allow for optimal policy determination as is standard in the literature (e.g. Becker 1968, Kaplow and Shavell 1994, Lott 1987, Polinsky and Rubinfeld 1991, Polinsky and Shavell 1984). Our interest, however, is not in deriving the optimal policy, but rather, in examining how individual criminal decisions respond to changes in observed policy, regardless of whether the policies implemented are optimal. 
$J_{l}(S)$. Initially, the sentence length $S$ is assumed to be one period. Later, when sentence enhancements are introduced, the enhancement will raise the sentence length to two periods.

The private return to crime (not including the punishment if detected) is denoted $r$ and is the only factor that varies across individuals. The return to the non-crime alternative is normalized to 0 for all individuals. Agents are assumed to be risk neutral and future utilities are not discounted, although either of those factors could be incorporated into the present framework (Polinsky and Shavell 1997). Thus, the agent's maximization problem in any period is simply $M A X \quad\left(r_{i}-p J_{i}(S)\right) C_{i}$ $C_{i t} \in\{0,1\}$

where $i$ indexes individuals. $C_{i t}$ is an indicator variable equal to one if a crime is committed by agent $i$ in period $t$, and zero otherwise. An agent commits crime if and only if the private return to crime $r$ exceeds the expected punishment $\left(p_{l} J_{1}\right)^{7}$ For simplicity, it is assumed that $r_{i}$ is uniformly distributed over agents with a range from 0 to $R$ and a density of $1 / R$. If there were no punishment, all agents would engage in criminal activities and the total crime rate $C_{l}$ would be equal to one. With a positive expected punishment, some agents will be deterred. In order to ensure an interior solution, $R$ is chosen such that $R>p_{t} J_{t}$. Thus, some agents will commit crimes in all periods, assuming they are not already incarcerated.

Because prison sentences from one period are served in the following period(s), crime in period $t$ depends not only on expected punishment in period $t$ (deterrence), but also on actual

${ }^{7}$ Implicit in equation 1 is the assumption that the criminal receives the utility of the criminal act even if caught and punished. This assumption is not necessary to obtain the results presented below. 
levels of crime and punishment in the preceding period(s) (incapacitation). ${ }^{8}$ It is relatively straightforward to demonstrate that the steady-state level of crime is as follows, ${ }^{9}$

$$
C_{t}=1-\frac{p_{t} J_{t}}{R}-p_{t}-{ }_{1} C_{t}-1
$$

If there were neither deterrence nor incapacitation, all agents would commit crime, leading to $C_{l}=1$. The second-term on the right-hand-side of equation 2 is deterrence; anyone with $r_{i}<p_{l} J_{t}$ decides against committing the crime. The final term in equation 2 is the number of crimes that do not occur as a result of incarceration (i.e. the incapacitation effect). In a steady-state, all agents who committed crime in the previous period will commit crime in the current period unless they are behind bars. Therefore the incapacitation effect is simply equal to the size of the prison population.

Setting crime in the current and preceding periods equal, the steady-state solution to the model solely in terms of parameters is

$C_{t}=\frac{\left(1-\frac{p_{t} J_{t}}{R}\right)}{1+p_{t}}$

\section{$\underline{\text { Introducing Sentence Enhancements }}$}

${ }^{8}$ Initially we consider prison sentences that are exactly one period in length. Thus, this period's crime depends only on last period's crime and punishment levels.

${ }^{9}$ Out of steady state, the equation becomes more complicated because the pool of prisoners may be composed of some agents who committed a crime last period, but would not engage in crime this period due to changes in the expected punishment. 
We model sentence enhancements as an increase in the prison sentence from one period to two periods. We assume that the probability of detection remains constant. ${ }^{10}$ In analyzing the effect of introducing sentence enhancements, it is critical to identify not only the new steady state, but also the transition path.

Assume that sentence enhancements are introduced in period $t$. Also, let the disutility of a two-period prison sentence be $(1+d) J$, where $d>0$, i.e. there is disutility associated with the second period in prison. We allow for the marginal disutility associated with increases in the prison term to be increasing $(d>1)$, decreasing $(d<1)$, or constant $(d=1)$. Crime in the first period with sentence enhancements in place is given by

$$
C_{t}=1-\left[\frac{p_{t} J_{t}}{R}+\frac{d p_{t} J_{t}}{R}\left(1-p_{t-1} C_{t}-1\right)\right]-p_{t-1} C_{t-1}
$$

The only difference between equations 2 and 4 is in the deterrence term, which is in square brackets in equation 4 . With sentence enhancements all agents who were previously deterred continued to be deterred. In addition, some additional agents are also deterred by the increased expected punishment. Note, however, that some agents who would be deterred if free are actually incarcerated, necessitating the $1-p_{t-1} * C_{t-1}$ term in the square brackets.

The two important observations emerging from a comparison of equations 2 and 4 are as follows. First, crime is lower in equation 4 due to the increased deterrence associated with longer sentences resulting from the sentence enhancements. Second, in the first period following the introduction of sentence enhancements, the incapacitation effect is unaffected. Not until the

\footnotetext{
${ }^{10}$ Although from the perspective of optimal policy design, holding $p$ fixed would not
} necessarily be optimal. 
original sentence expires does the increased incapacitation associated with sentence enhancements materialize. Thus, any immediate reduction in crime associated with sentence enhancements is attributable to deterrence rather than incapacitation.

The steady-state level of crime after the introduction of sentence enhancements is $C_{t}=1-\frac{(1+d) p_{t} I_{t}}{R}-\left(p_{t-1} C_{t-1}\right)-\left(p_{t-2} C_{t-2}\right)$

Comparing equations 2 and 5, the steady-state deterrence effect (the second term on the righthand-side of both equations) is greater after the sentence enhancement. This, of course, is a straightforward outcome of any economic model of crime. Comparing the first period after sentence enhancements to the steady state with such enhancements (equations 4 and 5), a more subtle result emerges. The deterrence effect associated with sentence enhancements increases over time. The explanation for this result is that initially some of those who could be deterred are incarcerated and therefore cannot respond to the change in incentives. Over time, those agents will be released from prison and deterred thereafter. ${ }^{11}$ Note that this channel for rising deterrence is separate from lags in behavioral changes on the part of criminals which are likely to be empirically relevant, but are not explicitly modeled.

Thus the initial change in crime represents a lower bound on the long-run increase in deterrence. This will have implications for the interpretation of the empirical results presented in

11 In some sense, the last italicized point is a relatively minor one from a public policy perspective since these agents are not committing crime either immediately after the sentence enhancements or in the steady state. The only difference is whether the reduction in crime is assigned to deterrence or incapacitation. The reason that this distinction is important, however, is that the measured reduction in crime directly following the introduction of sentence enhancements captures only the immediate rise in deterrence, not the long-run rise. 
later sections.

Solving for the steady-state crime rate in equation 5 solely in terms of parameters yields

$$
C_{t}=\frac{\left(1-\frac{(1+d) p_{t} J_{t}}{R}\right)}{1+2 p_{t}}
$$

Comparing equations 3 and 6, the steady-state crime rates before and after the sentence enhancements, crime is unambiguously lower with the enhancements. The change in deterrence is easily computed from equations 2 and 4 as $d p J / R$. Tedious algebraic manipulation of equations 3 and 6 (not shown) demonstrate that the change in the crime rate can either be greater than or less than the change in deterrence. Therefore, the introduction of sentence enhancements has an ambiguous impact on the incapacitation effect. Translated into more meaningful terms, this implies that the size of the prison population may either rise of fall with sentence enhancements. There are two countervailing forces affecting the prison population. Sentences are longer, but fewer crimes are committed so there are fewer criminals being sentenced.

\section{Section II: An overview of the use of sentence enhancements in the United States}

In recent years, many of the changes in sentencing policy that have been adopted have had one thing in common: they all impose mandatory, statutory increases in prison sentences on individuals who were already going to be incarcerated. Whether the new policies were called determinate sentencing laws, sentencing guidelines, gun enhancements, or repeat-offender enhancements, they all shared this common feature. By 1994, all 50 states and the Federal government had adopted one or more mandatory sentencing laws (Tonry 1996). In particular, 
repeat-offender enhancements were in use in 41 states and in the Federal sentencing guidelines as of 1993 (USSC 1991; BJA 1996).

In addition to those existing laws, 24 state legislatures enacted a new, more stringent breed of repeat-offender enhancements called 'Three Strikes and You're Out' laws (Clark et al. 1997) between 1993 and 1995. Repeat-offender enhancements can be characterized along two dimensions: the range of current crimes and criminal histories that qualify for the enhancement (scope) and the magnitude of the enhancement imposed (severity). Three-strikes laws toughened existing repeat-offender enhancements in both dimensions, expanding the scope of the enhancements beyond the most serious felons, and increasing the severity of the enhancements. In many states, three-strikes laws impose life imprisonment without parole for a third-time offender.

Furthermore, with the passage of the Violent Crime Control and Law Enforcement Act of 1994, the U.S. Congress made three-strikes sentencing a fundamental part of federal sentencing policy. First, the Act created a federal three-strikes law. The Act mandates life imprisonment for all serious violent federal felonies, if the defendant has been sentenced for two or more prior separate serious violent felonies or serious drug offenses in state or federal court (18 USC $3559(c)(1))$. Second, the Act provided incentives to states for increasing state penalties for repeat violent offenders. One way that a state can become eligible for a Truth-in-Sentencing Grant is to have in effect at the time of application laws requiring that violent felons who have been convicted of at least one prior separate serious violent felony or serious drug offence in state or federal court serve at least 85 percent of their sentence (42 USC 13702(a)(2)(D)).

Previous research on the impact of enhancements has reported conflicting findings on the 
aggregate impact of enhancements on crime. The only study of the effect of a three-strikes law, undertaken by RAND, predicted that California's 1994 law would have a substantial incapacitative effect on crime (Greenwood et al. 1994; but see Austin 1994 for a critique and Austin 1997 for evidence that these predictions have not been realized). Although some studies of the effect of gun enhancements report that adoption of enhancements reduces some or all gunrelated crimes (e.g., Pierce and Bowers 1981, McDowall et al. 1992), other studies of gun enhancements report no effect (e.g., Loftin et al. 1983, Loftin and McDowall 1984).

Disagreement in the literature extends to the existence and magnitude of the impact of increasing mandatory sentences on crime generally (see, e.g., Tonry 1992, 1996 and BJA 1996 for studies finding no effect).

Previous research, however, has failed to recognize both the importance and possibility of distinguishing between deterrence and incapacitation. ${ }^{12}$ Thus, further investigation of the effects of repeat-offender enhancements is essential to the analysis of recent changes in state and federal sentencing policy. Guided by our theoretical model, we exploit the transition path associated with the adoption of sentence enhancements. Short-run declines in crime are likely to be attributable largely or solely to deterrence since the incapacitative effect of sentence enhancements will occur only with a lag. Over time, continued declines in crime should continue as the full extent of deterrence is realized and incapacitation becomes operative. In the following section, we test the predictions of the model using California's experience with Proposition $8 .^{13}$

12 Indeed, the RAND study discussed above assumes that the California three-strikes law will have no deterrent effect at all in its assessment of the benefits and costs of the law.

13 As discussed in the concluding section of the paper, we have also examined states' experiences with three-strikes laws. Unlike Proposition 8, however, three-strikes laws have 


\section{Section III: Proposition 8 in California: The Effects of Repeat-Offender Enhancements ${ }^{14}$}

Proposition 8 was passed directly by California voters through the initiative process on June 8, 1982, and went into effect the next day. By adding Sections 667(a) and 1192.7(c) to the California Penal Code, Proposition 8 substantially increased both the scope and the severity of California's existing repeat-offender enhancement. ${ }^{15}$ Prior to the passage of Proposition 8 , the existing law required a three-year enhancement of violent felony offenders' sentences for each prior prison term served for a violent felony, or a one-year enhancement of nonviolent felony offenders' sentences for each prior prison term served for a nonviolent felony, whichever was greater. With Proposition 8, all "serious" felony offenders under Section 1192.7(c) received a five-year enhancement for each prior conviction of a "serious" felony offense, or a one-year enhancement for each prior prison term served for any offense, whichever was greater. (Section 1192.7(c) "serious" felonies include all "violent" felonies covered under the previous law as well as some nonviolent felonies, in particular burglary of a residence). In addition, Proposition 8 expanded the scope and severity of the enhancement by eliminating the statute of limitations in Section 667.5 that only considered a defendant's record for at most the past 10 years, by prohibiting judges from sentencing defendants to serve their enhancements concurrently with

generally not been rigorously enforced. Consequently, there is no evidence that punishments have actually increased as a result of three-strikes laws, except in California.

${ }^{14}$ The introduction to Section III draws heavily on Kessler and Piehl (1997).

${ }^{15}$ Prior to the passage of Proposition 8, California's Determinate Sentencing Law provided for several types of sentence enhancements: enhancements for causing great bodily injury, gun enhancements, and repeat-offender enhancements. At that time, Section 667.5 of the California Penal Code governed repeat-offender enhancements. 
their base sentence, and by requiring that each of the enhancements be served consecutively. ${ }^{16}$

Kessler and Piehl (1997) show that Proposition 8 increased sentences for repeat offenders charged with serious felonies but not for repeat offenders charged with certain nonserious felonies. ${ }^{17}$ Thus, because Proposition 8 affected punishment levels for some crimes but not for others, its passage provides an experiment with which we can evaluate the deterrent effect of repeat-offender enhancements.

Our investigation of the deterrent effects of Proposition 8 appears in Table 1. Table 1 presents a comprehensive list of the levels of and changes in consistently-defined crimes reported through the California Uniform Crime Reporting system in 1979, 1981, 1983, and 1985. The top panel of the table lists rates of serious felonies, e.g. those eligible for substantially-increased repeat-offender enhancements under Proposition 8. The bottom panel of the table presents those crimes that are not eligible under Proposition 8. Because Proposition 8 was passed by popular referendum, observed changes in crime around the time of its passage may reflect a combination of the true deterrent impact of harsher repeat-offender enhancements and of other factors

\footnotetext{
${ }^{16}$ The only data available is aggregated by crime category. Thus we are able to make comparisons between eligible and non-eligible crime categories, but not to differentiate between criminals who are or are not eligible for sentence enhancements.

${ }^{17}$ Kessler and Piehl (1997) also find small spillover effects of Proposition 8 affecting repeat offenders charged with "similar" nonserious felonies, where "similar" nonserious felonies are nonserious felonies that have legal elements in common with one or more serious felonies. However, spillover effects only strengthen our finding that increases in the scope and severity of repeat-offender enhancements attributable to Proposition 8 lead to decreases in crime. Because spillover effects increase sentences for "control" group crimes, they could only lead to decreases in the number of "control" group crimes, and therefore only lead to decreases in the magnitude of the estimated deterrent effect of Proposition 8 relative to rates of "control" group crimes. In contrast to Kessler and Piehl (1997), it should be noted that earlier research found no effect of Proposition 8 on sentence lengths (e.g., McCoy and Tillman 1986, Tillman and McCoy 1987).
} 
correlated with but not caused by the law change, such as changes in demographics, in other state policies, and in broad social norms against crime. This makes the availability of a control group of non-eligible crimes critical to the analysis.

Columns (5) and (6) list the percentage change in crime in the two years preceding and following the passage of the law. Prior to passage of Proposition 8 (1979-81), all of the crimes that were to be covered by the law were rising, as were a majority of the crimes unaffected by Proposition 8. On average, however, the eligible crimes were increasing at a faster rate than the non-eligible crimes. Taking a simple average across offenses in those two classifications, eligible crimes increased by 12.2 percent prior to Proposition 8 compared to 7.9 percent for the non-eligible crimes. ${ }^{18}$ Thus, there is no evidence of a pre-existing declining trend of eligible crimes, either in absolute terms or relative to non-eligible crimes.

In the years immediately following adoption of Proposition 8 , there is a dramatic decline in all five of the crime categories covered by the sentence enhancements, with an average decrease of 13.9 percent. The pattern among non-eligible crimes, on the other hand, is mixed. On average, these crimes declined by 2.8 percent, or less than one-fourth the amount of the eligible crimes. A standard differences-in-differences estimate of the "treatment" effect of Proposition 8 (percent change in eligible crimes minus percent change in non-eligible crimes) is -11.1 percent, as reported in the next to last row of column (6). Under the assumption that other determinants of the two crime categories were uncorrelated with the scope and passage of

\footnotetext{
${ }^{18}$ Taking a weighted average across crime types with the weights based on the number of offenses in the crime category does not materially affect our results. By using a simple average, we are placing additional weight per crime on those categories with fewer offenses, which also tend to be the most serious crimes.
} 
Proposition 8, this approach provides an unbiased estimate of the deterrent effect of the enhancement.

The estimates of the preceding paragraph ignore the fact that eligible crimes were increasing at a faster rate than non-eligible crimes prior to the passage of Proposition 8 . To the extent that there is persistence in such crime trends, simply looking at relative changes in crime after the law change will underestimate Proposition 8 's true impact. Therefore, the bottom row of the table reports changes in growth rates of eligible and non-eligible crimes before and after the law change. ${ }^{19}$ The implied impact of Proposition 8, -15.4 percent (as reported in the bottom row of column (6)), is larger than the estimate that ignores the pre-existing trends in crime.

The immediacy with which crime in the eligible categories responded to the passage of Proposition 8 implies the presence of a large deterrent effect. It is worth noting that this strong finding with respect to the effectiveness of increasing the severity of punishment is unusual; most of the previous literature has found that changes in the certainty of punishment are much better predictors of changes in crime rates than are changes in severity (e.g. Grogger 1991). ${ }^{20}$

Our theoretical model predicts not only an immediate decline in crime with the adoption of sentence enhancements, but also a continued decline over the longer run as incapacitation

19 Expressed in terms of the values in the various columns, the change in growth rates is $((($ column 6 eligible $)$ - (column 5 eligible $))$ - ((column 6 non-eligible $)$ - (column 5 noneligible))).

${ }^{20}$ Past findings of a greater impact of punishment certainty relative to punishment severity are consistent with our arguments earlier in the paper that typical estimates of the economic model of crime confound deterrence and incapacitation. Increases in punishment certainty will result in an immediate increase in both deterrence and incapacitation. Increases in punishment severity, on the other hand, will only have immediate deterrence effects, with incapacitation effects occurring only with a lag. 
effects and further deterrence incrementally take hold. Column (7) presents the percent change in crime for each type of offense over the period 1981-85. The eligible crimes, on average, stay constant between 1983 and 1985 (i.e. there is no difference between the mean effect in columns (6) and (7). In contrast, the non-eligible crimes see a substantial increase between 1983 and 1985. Thus, by 1985 , crime rates are 4.6 percent higher on average for the non-eligible crimes than they were prior to the passage of Proposition 8. As the differences-in-differences estimator in the next to last row of column (7) demonstrates, the longer run decline in eligible crime categories is 18.5 percent, almost twice as large as the short run decline reported in column (6). The differences-in-differences estimator in growth rates comparing 1981-85 to $1979-81$ is -22.8 percent, compared to -15.4 percent in column (6). Although not presented in the table, it is worth noting that the observed pattern continues through 1987; by that year the cumulative relative decline in eligible crimes relative to non-eligible crimes is greater than 30 percent. These result suggests that, as predicted by the model, crime does not fall immediately to its steady state level, but rather falls steadily along a transition path as the incapacitation effect is incorporated.

While the results in Table 1 are consistent with a large deterrent effect associated with Proposition 8, it is important to consider other possible explanations for the observed patterns. One alternative story involves the differential responsiveness of violent and property crimes to economic conditions. Cantor and Land (1985), Devine et al. (1988), and Levitt (1997) find that property crime is counter-cyclical, whereas violent crime is not strongly affected by the economy. The magnitude of this effect, however, is small relative to the apparent impact of Proposition 8. Of the three papers cited above, Levitt (1997) finds the largest estimate of unemployment on property crime: each percentage point of unemployment corresponds to a one percent increase in 
property crime. From 1981 and 1983, the unemployment rate in California increased from 7.4

percent to 9.7 percent. Changing employment conditions might therefore account for up to a 2.5 percent difference between eligible and non-eligible crimes, out of an overall difference of over 11 percent. Between 1981 to 1985 unemployment rates in California were virtually unchanged (7.4 percent versus 7.2 percent). Thus, economic fluctuations cannot explain the pattern of eligible and non-eligible crimes over that time period.

A second possible explanation for the patterns observed in Table 1 would be an increase in the certainty of punishment for eligible crimes relative to non-eligible crimes after the passage of Proposition 8. In practice, however, just the opposite appears to have occurred. Between 1981 and 1985, the arrest rate (i.e. arrests in a crime category divided by reported crimes in that category) in California fell for two of the three eligible crime categories (homicide and robbery) for which we are able to obtain comparable arrest data. ${ }^{21}$ In contrast, arrest rates rose between 1981 and 1985 for larceny and motor vehicle theft, the two non-eligible crimes for which comparable arrest data are available.

A third alternative explanation for our results is that the patterns in the data reflect general changes in crime patterns that are not specific to California and therefore cannot be attributed to Proposition 8. To test this hypothesis, we consider two alternative groups of control states: (1) those that share a border with California (Arizona, Nevada, and Oregon), and (2) the most populous states (Florida, Illinois, New York, and Texas). For both sets of controls, we have

21 Arrest data is available only for the seven FBI index I crime categories, not the more detailed crime categories reported in Table 1. Consequently, in the arrest data we cannot distinguish between aggravated assaults with and without a handgun, or burglaries of residences and non-residences. 
replicated the analysis of Table 1 replacing eligible and non-eligible crimes with the FBI's violent and property crime categories respectively due to data limitations. In both control groups, violent crime rates rose faster than property crime between 1981 and 1983 (4.2 and 3.0 percent in the respective control groups) and between 1981 and 1985 ( 8.6 and 4.1 percent). This is in stark contrast to California's Proposition 8 experience: eligible crimes fell 11.1 and 18.5 percent relative to non-eligible crimes over those two periods.

A fourth possible problem with the simple approach in Table 1 is that the non-eligible crimes are not closely related enough to the eligible crimes to provide a useful control. If this is the case, than looking at the most similar crime categories across those two groups might provide a better basis for comparison. Comparing burglary of a residence (eligible) and burglary of a non-residence (non-eligible), the eligible crime falls by an additional 15 percent between 1981 and 1983 , and by 5.6 percent between 1981 and 1985 . Comparing aggravated assault with a firearm (eligible) to aggravated assault without a firearm (non-eligible) the eligible crime falls by an additional 21.2 percent and 26.0 percent over the two periods. Thus, comparing the most similar crime patterns supports the broader findings. Note, however, that the more similar the crime categories, the more likely it is that criminals will substitute away from eligible crimes toward non-eligible crimes because of the increased penalties for the former (Levitt 1998). Thus, focusing exclusively on the most closely matched pairs of crimes may lead to a systematic overestimate of the true reduction in crime due to the sentence enhancements.

\section{$\underline{\text { Section IV: Discussion and conclusions }}$}

This paper demonstrates theoretically that sentence enhancements provide a means of 
distinguishing deterrence from incapacitation. Because enhancements are tacked on to prison sentences that would have been served anyway, there is no immediate incapacitation effect associated with such enhancements. Thus any immediate decrease in crime that is observed is attributable to deterrence. In the long run, however, both the full deterrent effect and incapacitation of sentence enhancements becomes operative. Consequently, crime will not fall immediately to the new steady state, but rather decline gradually over time. The predictions of the model are borne out in an empirical application using eligible and non-eligible crimes for California's Proposition 8. Crimes that were affected by the sentence enhancements in Proposition 8 fall by over 10 percent relative to crimes that were not covered in the first year after the law change. Three years later, the eligible crimes are roughly 20 percent lower. These results suggest the presence of a strong deterrent effect, but also some potential role for incapacitation.

Our results suggest that criminals respond to the severity and not just the certainty of sentences, a result that is predicted by the economic model of crime, but has proven elusive empirically. This suggests that the increasing reliance on sentence enhancements in both state law and the federal sentencing guidelines may represent an effective means of reducing crime. To the extent that sentence enhancements target the most frequent and dangerous offenders, such measures may be more cost-effective than further expanding the prison population through the incarceration of the marginal criminal who, given the skewed distribution of crime involvement (DiIulio and Piehl 1991), is likely to impose relatively low crime-related costs on society.

These results, if generalizable, have important implications for three-strikes laws. If deterrence is the primary reason for crime reduction with such laws, then they represent an 
attractive public policy option: both equilibrium crime rates and prison populations will fall. In contrast, if all of the reduction in crime were due to incapacitation, three-strikes laws are inefficient because they lead to the long-term incarceration of individuals who are no longer criminally active. Our findings suggest that the answer likely lies somewhere in the middle. There are important behavioral responses to increased punishments on the part of criminals, but increased incapacitation appears to play a role as well.

Unfortunately, a direct empirical test of the impact of three-strikes is not possible because of the failure of states to enforce such laws in spite of having them on the books. Of the 24 states passing three-strikes laws since 1993, only California has widely applied these statutes. In California, 3,281 individuals had been sentenced under three-strikes laws as of June 1, 1997 (Austin 1997). Washington, the first state to pass a three-strikes law and after California the most active state in applying the law, has sentenced only 97 prisoners under the statute. In most states, three-strikes statutes have never been enforced. Consequently, it is not surprising that passage of three-strikes laws is not associated with any discernible change in either crime rates or imprisonment rates, except perhaps in California. Between 1993 and 1996 (three-strikes laws were implemented in 1994), California has seen a 20 percent decline in violent crime per capita and a 19 percent decline in property crime per capita. In comparison, violent crime has fallen 13 percent in the rest of the nation, and property crime is down only 4 percent over the same period. California's prison population has grown at roughly the same rate as the nation as a whole since adoption ( 22 percent versus 21 percent). In fact, contrary to the dire predictions of Greenwood et al. (1994) concerning the explosion in California's prison population as a consequence of three strikes, the current prison population is at almost exactly the level projected without the passage 
of three-strikes law. ${ }^{22}$ Without further investigation, however, it is difficult to know whether declining crime in California can be causally attributed to the presence of three strikes. ${ }^{23}$

The reasons underlying the failure to enforce three-strikes laws in most states merits greater attention, especially given that a wide variety of other enhancements are frequently enforced at both the state and federal level. The two notable differences between three-strikes laws and other enhancements are (1) the much narrower applicability of three-strikes in most states, and (2) the extremely harsh penalties associated with three-strikes. Together, these two features lead to horizontal inequity, i.e. offenders convicted of relatively similar offenses will be treated in a radically different manner. Combined with the fact that the third-strike penalty is often out-of-line with the third-strike offense (almost 40 percent of third strikes in California were for property offenses and another 11 percent were for drug possession), prosecutors and judges appear to exercise discretion in circumventing the statutes (as in Andreoni 1991). The observed failure of most jurisdictions to enforce three-strikes laws suggests that from the perspective of fighting crime, sentence enhancements that are broader in scope and less punitive, such as Proposition 8, may ultimately prove more effective.

${ }^{22}$ In defense of Greenwood et al. (1994), one partial explanation for the lack of impact of three strikes on the prison population is the uneven application of the law by judges and prosecuters.

${ }^{23}$ Unfortunately it is not possible to conduct an analysis of the three strikes law in California paralleling that for Proposition 8 because conviction of any felony triggers the application of the three-strikes enhancement. Thus, for three strikes, there is no good counterpart to the non-eligible crimes used as controls in the Proposition 8 analysis. 


\section{$\underline{\text { References }}$}

Austin, James, "'Three Strikes and You're Out': The Likely Consequences on the Courts, Prisons, and Crime in California and Washington State," St. Louis University Public Law Review 14: 239-57 (1994).

Austin, James, “, Presented at the American Criminological Society meetings, November 1997.

Becker, Gary, 1968, "Crime and Punishment: An Economic Approach," Journal of Political Economy 76:169-217.

Blumstein, Alfred, "Prisons," in J. Q. Wilson and J. Petersilia (eds), Crime (San Francisco, CA: Institute for Contemporary Studies, 1995).

Bureau of Justice Assistance, "National Assessment of Structured Sentencing," (Washington, DC: U.S. Department of Justice/Office of Justice Programs, NCJ 153853, 1996).

California Bureau of Criminal Statistics, Crime and Delinquency, 1979-85, (Sacramento, CA: California Department of Justice).

Cameron, Samuel, "The Economics of Crime Deterrence: A Survey of Theory and Evidence," Kyklos 41:301-323 (1988).

Cantor, David, and Kenneth Land, "Unemployment and Crime Rates in the Post-World War II United States: A Theoretical and Empirical Analysis," American Sociological Review 50:317-332 (1985).

Clark, John, Austin, James, and D. Alan Henry, “Three Strikes and You're Out': A Review of State Legislation," (Washington, DC: U.S. Department of Justice/Office of Justice Programs, NCJ 165369, 1997).

Devine, Joel, Joseph Sheley, and Dwayne Smith, "Macroeconomic and Social-Control Policy Influences on Crime Rate Changes, 1948-1985," American Sociological Review 53:407420 (1988).

Dilulio, John, and Anne Piehl, 1991, "Does Prison Pay? The Stormy National Debate over the Cost-Effectiveness of Imprisonment," The Brookings Review (fall), 28-35.

Ehrlich, Isaac, "Participation in Illegitimate Activities: A Theoretical and Empirical Investigation," Journal of Political Economy 81:531-567 (1973).

Ehrlich, Isaac, "Crime, Punishment, and the Market for Offenses," Journal of Economic Perspectives 10:43-67, 1996. 
Flynn, Edith E. et al., "Three Strikes Legislation: Prevalence and Definitions," in Critical Criminal Justice Issues: Task Force Reports From the American Society of Criminology to Attorney General Janet Reno, (Washington, DC: U.S. Department of Justice/Office of Justice Programs, NCJ 158837, 1997).

Greenwood, Peter et al., "Three Strikes and You're Out: Estimated Benefits and Costs of California's New Mandatory Sentencing Law," (Santa Monica, CA: RAND, 1994).

Grogger, Jeff, "Certainty vs. Severity," Economic Inquiry 29:297-309 (1991).

Kaplow, Louis, and Steven Shavell, "Optimal Law Enforcement with Self-Reporting of Behavior," Journal of Political Economy 102:583-606 (1994).

Kessler, Daniel and Anne Morrison Piehl, "The Role of Discretion in the Criminal Justice System," (Stanford University Mimeo 1997).

Levitt, Steven, "Using Electoral Cycles in Police Hiring to Estimate the Effect of Police on Crime," American Economic Review 87:270-290 (1997)

Levitt, Steven, "Why Do Increased Arrest Rates Appear to Reduce Crime: Deterrence, Incapacitation, or Measurement Error?" Forthcoming, Economic Inquiry (1998).

Loftin, Colin, Milton Heumann, and David McDowall, "Mandatory Sentencing and Firearms Violence: Evaluating an Alternative to Gun Control," Law and Society Review 17: 287 318 (1983).

Lott, John, "Should the Wealthy Be Able to Buy Justice?" Journal of Political Economy 95:1307-1316 (1987).

Marvell, Thomas, and Carlisle Moody, 1994, "Prison Population Growth and Crime Reduction," Journal of Quantitative Criminology 10:109-140 (1994).

Marvell, Thomas, and Carlisle Moody, "Police Levels, Crime Rates, and Specification Problems," Criminology 34:609-646 (1996).

Mayhew, Patricia, Ronald Clarke, John Burrows, J. Mike Hough, and Stuart Winchester, 1979, "Crime in Public View," Home Office Research Study No. 49, London.

McCormick, Robert, and Robert Tollison, "Crime on the Court," Journal of Political Economy 92:223-235 (1984).

McCoy, Candace and Tillman, Robert "Controlling Felony Plea Bargaining in California: The Impact of the 'Victims' Bill of Rights,"' Bureau of Criminal Statistics, (Sacramento, CA: California Department of Justice, 1986). 
McDowall, David, Loftin, Colin, and Wiersema, Brian, "A Comparative Study of the Preventive Effects of Mandatory Sentencing Laws for Gun Crimes," Journal of Criminal Law and Criminology 83: 378-394 (1992).

Nagin, Daniel, "Criminal Deterrence Research: A Review of the Evidence and a Research Agenda for the Outset of the $21^{\text {st }}$ Century," Unpublished manuscript, Carnegie Mellon University (1997).

Pierce, Glen L. and William J. Bowers, "The Bartley-Fox Gun Law's Short-Term Impact on Crime in Boston," Annals of the American Academy of Political and Social Science 455: $120-32(1981)$

Polinsky, A. Mitchell, and Daniel Rubinfeld, "A Model of Optimal Fines for Repeat Offenders," Journal of Public Economics 46:291-306 (1991).

Polinsky, A. Mitchell, and Steven Shavell, "The Optimal Use of Fines and Imprisonment," Journal of Public Economics 24:89-99 (1984).

Polinsky, A. Mitchell, and Steven Shavell, "On the Disutility and Discounting of Imprisonment and the Theory of Deterrence," Harvard Law School Working Paper (1997).

Spelman, William, Criminal Incapacitation (New York, NY: Plenum Press, 1994).

Tauchen, Helen, Anne Witte, and Harriet Griesinger, 1993, "Criminal Deterrence: Revisiting the Issue with a Birth Cohort," Mimeo, Department of Economics, University of North Carolina at Chapel Hill.

Tillman, Robert, and McCoy, Candace, "The Impact of California's 'Prior Felony Conviction' Law," Bureau of Criminal Statistics, (Sacramento, CA: California Department of Justice, 1986).

Tonry, Michael, "Structuring Sentencing," in Michael Tonry and Norval Morris, eds., Crime and Justice: A Review of Research, Volume 10 (Chicago: University of Chicago Press, 1988).

, "Mandatory Penalties," in Michael Tonry, ed., Crime and Justice: A Review of

Research. Volume 16 (Chicago: University of Chicago Press, 1992). , Sentencing Matters (New York: Oxford University Press, 1996).

United States Sentencing Commission, "The Federal Sentencing Guidelines: A Report on the Operation of the Guidelines System and Short-Term Impacts on Disparity in Sentencing, Use of Incarceration, and Prosecutorial Discretion and Plea Bargaining," (Washington, DC: U.S. Sentencing Commission, 1991).

Visher, Christy, "The RAND Inmate Survey: A Reanalysis," in Blumstein, A. et al. (eds.), 
Criminal Careers and "Career Criminals," Volume II, (National Academy Press: Washington, D.C., 1986).

Witte, Ann, "Estimating the Economic Model of Crime with Individual Data," Quarterly Journal of Economics 94:57-84 (1980). 


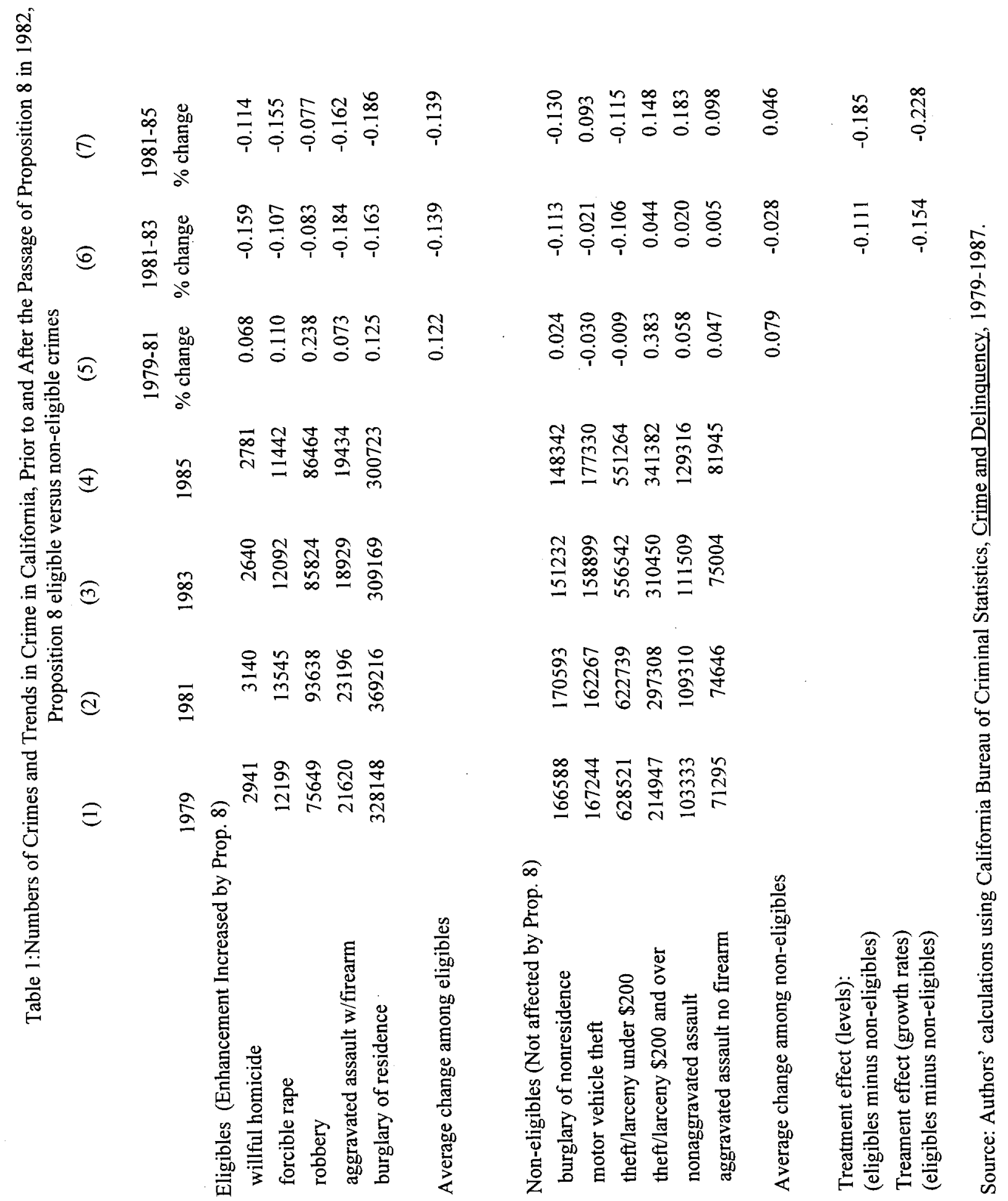

